\title{
CHEMICAL SHIFTS AT $K$-ABSORPTION EDGES OF TRANSITION METALS ADMIXED TO ZnS AND ZnSe
}

\author{
R.J. IWANOWSKI, K. ŁAWNICZAK-JABLOŃSKA \\ Institute of Physics, Polish Academy of Sciences \\ Al. Lotników 32/46, 02-668 Warsaw, Poland
}

and A. Traverse

Laboratoire pour l'Utilisation du Rayonnement Electromagnetique Universite de Paris-Sud, Batiment 209D, 91405 Orsay, France

This paper gives the experimental evidence of systematic X-ray $K$-absorption edge studies in an effort to analyse the effect of cation chemical shift in the group of compounds type $\mathrm{Zn}_{1-x} \mathrm{M}_{x} \mathrm{~A}(\mathrm{M}=\mathrm{Mn}, \mathrm{Fe}, \mathrm{Co}, \mathrm{Ni} ; \mathrm{A}=\mathrm{S}, \mathrm{Se})$. The observed chemical shift was found practically independent of the choice of anion, whereas it revealed a noticeable decrease when passing from $\mathrm{Mn}$ to $\mathrm{Zn}$. The effect was ascribed to the change of the $3 d$ shell occupation. The calculations of the effective cation charge (based on the theoretical approach of Kitamura and Chen, 1991) have shown that in the case of transition metals admixed to $\mathrm{ZnS}$ and $\mathrm{ZnSe}$ there is a contribution of the $3 d$ electrons to the overall charge transfer, which indicates that the ability of $3 d$ electrons to participate in predominantly ionic bond decreases with $3 d$ orbit filling.

PACS numbers: $78.70 . \mathrm{Dm}$

\section{Introduction}

It is well known that X-ray absorption spectra are sensitive to the chemical environment of the absorbing atoms under investigation [1]. Amongst the different chemical effects that are observed on X-ray discontinuities, considerable attention has been paid to the change in the position of the main edges, i.e. the chemical shift $(D)$. Numerous papers were devoted to the chemical shifts of $K$ - or $L$-absorption spectra of metals and their compounds. In particular, various possible qualitative explanations, based on, e.g., oxidation state [2], electronegativity [3], effective ionic charge $[4,5]$, hybridization $[3,6]$, ionicity $[7,8]$, coordination number $[9]$, etc., have been put forward to account for these shifts. Quite recently, Kitamura and Chen [10] have performed, for selected transition metals, the self-consistent calculations of the $K$-absorption edge energy and its chemical shift on the basis of 
the atomic nature (instead of using the multiple scattering approach) thus limiting their application mainly to the ionic solids.

During last years our main research effort concerned the systematic studies of X-ray absorption near-edge structure (XANES) at the $K$-edge of cations (and anions) in the $\mathrm{Zn}_{1-x} \mathrm{M}_{x} \mathrm{~S}$ and $\mathrm{Zn}_{1-x} \mathrm{M}_{x}$ Se ternary compounds ( $\mathrm{M}-$ being $\mathrm{Mn}$, $\mathrm{Fe}, \mathrm{Co}, \mathrm{Ni})[11,12]$. This has obviously determined our interest in the chemical shifts at the $K$-absorption edges of transition metals admixed to $\mathrm{ZnS}$ and $\mathrm{ZnSe}$ and, furthermore, in their description in terms of the theoretical approximation given in Ref. [10].

\section{Experiment}

$\mathrm{Zn}_{1-x} \mathrm{M}_{x} \mathrm{~S}$ and $\mathrm{Zn}_{1-x} \mathrm{M}_{x} \mathrm{Se}(\mathrm{M}=\mathrm{Mn}, \mathrm{Fe}, \mathrm{Co}, \mathrm{Ni})$ mixed crystals were grown at the Institute of Physics, Polish Academy of Sciences. The compounds containing $\mathrm{Co}$ and $\mathrm{Ni}$ were prepared by chemical vapour transport using iodine as a transport agent. Solid solutions admixed with $\mathrm{Mn}$ or Fe were grown by the triple sintering of $\mathrm{ZnS}$ and $\mathrm{ZnSe}$ with appropriate monochalcogenides of transition metals at $1200^{\circ} \mathrm{C}$.

The composition of these alloys $(x)$ has precisely been determined with the use of electron microprobe JEOL JSM-50A. X-ray diffraction studies were performed by a conventional X-ray powder diffractometer $\left(\mathrm{Cu} K_{\alpha}\right)$. Besides the $\mathrm{Zn}_{1-x} \mathrm{Mn}_{x} \mathrm{~S}$ specimens, which crystallize in a wurzite structure, the rest of the crystals studied had a zinc-blende structure.

The XANES spectra at the $K$-edge of $\mathrm{Mn}, \mathrm{Fe}, \mathrm{Co}, \mathrm{Ni}$ and $\mathrm{Zn}$ have been recorded at room temperature in the transmission or fluorescence mode using synchrotron radiation at the XAS1 station of the DCI ring at Laboratoire pour l'Utilisation du Rayonnement Electromagnetique, Orsay, France. The Si(331) channel-cut crystal monochromator provided a spectral range of $6-30 \mathrm{keV}$ with an energy resolution of $\Delta E / E \approx 10^{-4}$. The storage ring was operating at $E=$ $1.85 \mathrm{GeV}$, with a beam current ranging within 200-300 mA. The XANES data range was usually fixed between -30 and $100 \mathrm{eV}$, with reference to the $K$-edge position.

A prevailing part of the absorption spectra was recorded in the transmission mode. In particular cases, when the concentration of the admixed transition metal $(x)$ was too small for detection of its $K$-edge in the transmission mode, the fluorescence detection had to be applied. This concerned the cases of $\mathrm{Ni}$ in $\mathrm{ZnS}$ as well as $\mathrm{Co}$ and $\mathrm{Ni}$ in $\mathrm{ZnSe}$. For each set of $K$-edge XANES runs the energy scale was calibrated by a measurement of the corresponding pure metal (M, Zn) as reference. The XANES spectra at the $K$-edges of cations, considered in this paper, have been published earlier [11, 12] together with additional experimental details and discussion [12].

\section{Results and discussion}

The chemical shifts $(D)$ of the $K$-edge threshold energies $\left(E_{0}\right)$ for selected transition metals in $\mathrm{Zn}_{1-x} \mathrm{M}_{x} \mathrm{~S}$ and $\mathrm{Zn}_{1-x} \mathrm{M}_{x} \mathrm{Se}(\mathrm{M}=\mathrm{Mn}, \mathrm{Fe}, \mathrm{Co}, \mathrm{Ni})$ alloys, together with respective data for $\mathrm{Zn} K$-edge in $\mathrm{ZnS}$ and $\mathrm{ZnSe}$, were collected in Table. The position of the $K$-absorption threshold was determined from a maximum of the first derivative within its main slope - a standard procedure for 
TABLE

Experimental values of the chemical shift at the metal $K$-absorption edge for $\mathrm{Zn}_{1-x} \mathrm{M}_{x} \mathrm{~A}$ compounds, where $\mathrm{M}=\mathrm{Mn}, \mathrm{Fe}, \mathrm{Co}, \mathrm{Ni}$ and $\mathrm{A}=\mathrm{S}$, Se. The absolute threshold energies of the $K$-edges for elemental metals (from Ref. [14]), used as references, are given in brackets. The cation charges, predicted from the theoretical estimates of Ref. [10], are also indicated.

\begin{tabular}{|c|c|c|c|}
\hline $\begin{array}{c}K \text {-edge } \\
\text { Element (energy) }\end{array}$ & Material & $\begin{array}{c}\text { Chemical } \\
\text { shift } D[\mathrm{eV}]\end{array}$ & $\begin{array}{c}\text { Predicted } \\
\text { charge } q[\mathrm{e}]\end{array}$ \\
\hline \multirow[t]{7}{*}{$\mathrm{Mn}(6539.0 \mathrm{eV})$} & $\mathrm{Zn}_{1-x} \mathrm{Mn}_{x} \mathrm{~S}$ & & \\
\hline & $x=0.12$ & 8.0 & 2.46 \\
\hline & $x=0.20$ & 8.0 & 2.46 \\
\hline & $x=0.33$ & 8.0 & 2.46 \\
\hline & $\mathrm{Zn}_{1-x} \mathrm{Mn}_{x} \mathrm{Se}$ & & \\
\hline & $x=0.21$ & 7.6 & 2.41 \\
\hline & $x=0.31$ & 8.0 & 2.46 \\
\hline \multirow[t]{7}{*}{$\mathrm{Fe}(7112.0 \mathrm{eV})$} & $\mathrm{Zn}_{1-x} \mathrm{Fe}_{x} \mathrm{~S}$ & & \\
\hline & $x=0.11$ & 7.5 & 2.34 \\
\hline & $x=0.24$ & 7.8 & 2.37 \\
\hline & $x=0.50$ & 7.5 & 2.34 \\
\hline & $\mathrm{Zn}_{1-x} \mathrm{Fe}_{x} \mathrm{Se}$ & & \\
\hline & $x=0.08$ & 6.9 & 2.28 \\
\hline & $x=0.18$ & 7.0 & 2.29 \\
\hline \multirow[t]{7}{*}{$\mathrm{Co}(7708.9 \mathrm{eV})$} & $\mathrm{Zn}_{1-x} \mathrm{Co}_{x} \mathrm{~S}$ & & \\
\hline & $x=0.10$ & 7.3 & 2.30 \\
\hline & $x=0.16$ & 7.3 & 2.30 \\
\hline & $x=0.25$ & 7.3 & 2.30 \\
\hline & $\mathrm{Zn}_{1-x} \mathrm{Co}_{x} \mathrm{Se}$ & & \\
\hline & $x=0.02$ & 6.5 & 2.22 \\
\hline & $x=0.07$ & 7.5 & 2.31 \\
\hline \multirow[t]{4}{*}{$\mathrm{Ni}(8332.8 \mathrm{eV})$} & $\mathrm{Zn}_{1-x} \mathrm{Ni}_{x} \mathrm{~S}$ & & \\
\hline & $x=0.01$ & 6.3 & 2.27 \\
\hline & $\mathrm{Zn}_{1-x} \mathrm{Ni}_{x} \mathrm{Se}$ & & \\
\hline & $x=0.01$ & 5.0 & 2.15 \\
\hline \multirow[t]{2}{*}{$\mathrm{Zn}(9658.6 \mathrm{eV})$} & $\operatorname{ZnS}$ & 2.1 . & 1.91 \\
\hline & $\mathrm{ZnSe}$ & 2.1 & 1.91 \\
\hline
\end{tabular}

estimating $E_{0}$ (e.g. $\left.[8,13]\right)$. The chemical shifts listed in Table were obtained from a simple subtraction of the experimental $E_{0}$ value for $\mathrm{M}$ (or $\mathrm{Zn}$ ) in an alloy and in a respective pure metal. The absolute $K$-edge threshold energies were set by 
assigning the measured $E_{0}$ values for elemental metals to their known reference values. These latter were taken from Ref. [14] and were inserted in brackets in Table.

Judging from Table, the chemical shift for the transition metals studied is independent of their content $(x)$ in $\mathrm{ZnS}$ and $\mathrm{ZnSe}$. Also, within the accuracy of determining $D(\mp 0.5 \mathrm{eV})$, it does not practically depend on the choice of matrix (here: $\mathrm{ZnS}$ or $\mathrm{ZnSe}$ ). On the other hand, the magnitude of chemical shift for the admixed transition metals (M) exhibits a declining tendency when varying the $\mathrm{M}$ component in an alloy from $\mathrm{Mn}$ to $\mathrm{Ni}$ - finally, the minimum $D$ value was reached for $\mathrm{Zn}$ in $\mathrm{ZnS}$ and $\mathrm{ZnSe}$. Such evidence indicates that the observed chemical shift is independent of the choice of the nearest-neighbours ( $\mathrm{S}$ or Se) and of the composition of the second coordination shell ( $\mathrm{Zn}$ and admixed transition metal), thus suggesting that the effect mainly originates from the atomic structure of the absorbing ion. In fact, for particular alloy (e.g. $\mathrm{Zn}_{1-x} \mathrm{M}_{x} \mathrm{~S}$ ) the substitution of a given transition metal by the other one results in the change of a number of $3 d$ electrons.

The chemical shift strongly depends on a charge transfer in the ionic bond. A high degree of ionicity of the chemical bond in $\mathrm{ZnS}$ and $\mathrm{ZnSe}$ (in both cases $f_{i}=0.63$ [8]) has justified us to estimate the effective cation charge $(q)$ from the chemical shifts $(D)$ at the $K$-edges in terms of the theoretical approach of Kitamura and Chen [10], which is based on the atomic nature of the absorber. They have made self-consistent-field calculations of the chemical shift as a function of the cation charge for different transition metal (and $\mathrm{Zn}$ ) ions, $(\mathrm{M})^{+q}$. The values of the predicted cation charge, corresponding to our experimental chemical shifts, were also inserted in Table.

It can be noticed from Table that for $\mathrm{Zn}$ in both $\mathrm{ZnS}$ and $\mathrm{ZnSe}$ we obtained the cation charge equal 1.91 (in "e" units - see Table), which remains very close to its formal value $(q=2)$. This provided us a reasonable preliminary verification of the Kitamura approximation [10] for our case.

One should pay here special attention to the problem of reliability of the applied experimental data. For example, Kitamura and Chen [10] received the value $q=2.3$ for the cation charge of $\mathrm{Zn}$ in $\mathrm{ZnS}$, when taking $D=5.68 \mathrm{eV}$ from Ref. [8]. However the authors of Ref. [8] have performed their measurements in the standard laboratory spectrometer, instead of using synchrotron radiation source as in the recent case, thus loosing the accuracy which remains crucial for relatively low $D$ values for $\mathrm{Zn}$.

The estimates of the effective charge for transition metals in the host matrices studied (Table) enabled us to find a certain correlation: their cation charge tends to decrease with filling of the $3 d$ electron shell, from the highest value of $q=2.46$ for $\mathrm{Mn}$ down to 1.91 for $\mathrm{Zn}$. This qualitatively reproduces the above-mentioned dependence of the chemical shift with the number of $3 d$ electrons (Table). Thus, an increased occupation of the transition metal $3 d$ shell results in a weakened capability of the $3 d$ electrons for participation in the predominantly ionic bond, which manifests itself in a rise of their core-like character. Figure 1 gives the compendium of the predicted cation charge $(q)$ vs. $3 d$ shell filling, based on the data of Table. Taking into account the accuracy of estimating the charge, i.e. 


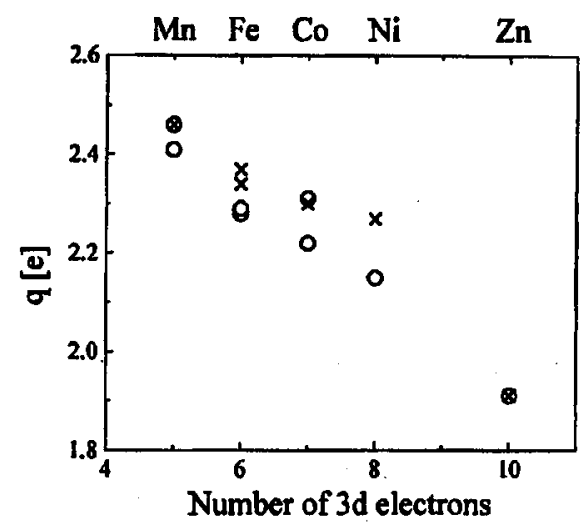

Fig. 1. Effective cation charge (calculated after Kitamura and Chen [10]) for Zn and selected transition metals ( $\mathrm{M}=\mathrm{Mn}, \mathrm{Fe}, \mathrm{Co}, \mathrm{Ni}$ ), admixed to $\mathrm{ZnS}$ (crosses) and $\mathrm{ZnSe}$ (circles) compounds. For details see text.

$\Delta q=\mp 0.05$ for $\mathrm{Mn}, \mathrm{Fe}, \mathrm{Co}, \mathrm{Ni}$ and $\Delta q=\mp 0.25$ for $\mathrm{Zn}$, one can deduce that $q$ vs. $3 d$ shell filling dependence is practically the same for both baseline compounds, $\mathrm{ZnS}$ and $\mathrm{ZnSe}$.

\section{Conclusions}

This paper gives the experimental evidence of systematic X-ray $K$-absorption edge studies in an effort to analyse the effect of the cation chemical shift in the group of compounds type $\mathrm{Zn}_{1-x} \mathrm{M}_{x} \mathrm{~A}(\mathrm{M}=\mathrm{Mn}, \mathrm{Fe}, \mathrm{Co}, \mathrm{Ni} ; \mathrm{A}=\mathrm{S}, \mathrm{Se})$. It has been found there that the chemical shift is practically independent of the nearest ( $\mathrm{S}$ or $\mathrm{Se}$ ), and the second nearest-neighbours ( $\mathrm{Zn}$ and $\mathrm{M}$ atoms). This, together with the identical crystal structure (ZnS-type) in the case considered, led us to ascribe the decrease in the cation chemical shift (when passing from $\mathrm{Mn}$ to $\mathrm{Zn}$ ) to the influence of the atomic structure of the absorbing cation, i.e. to the change of the $3 d$ shell configuration. It has justified to calculate the effective cation charge $(q)$ from the experimental chemical shifts on the base of the theoretical estimates of Ref. [10]. The obtained $q$ vs. $3 d$ shell filling dependence has proved that in the case of transition metals admixed to $\mathrm{ZnS}$ and $\mathrm{ZnSe}$, besides the electrons from $4 s$ orbital, also the $3 d$ electrons effectively contribute to the overall charge transfer.

\section{References}

[1] D.J. Nagel, W.L. Baum, in: X-Ray Spectroscopy, Ed. L.V. Azarof,, McGraw-Hill, New York 1974, p. 445.

[2] A.K. Nigam, M.K. Gupta, J. Phys. F 3, 1251 (1973).

[3] S. Kwata, K. Maeda, J. Phys. C 11, 2391 (1978).

[4] J.P. Suchet, F. Bailly, Ann. Chem. 10, 517 (1965).

[5] P.R. Sarode, S. Ramesha, W.H. Madhusudan, C.N.R. Rao, J. Phys, C 12, 2439 (1979).

[6] V.G. Bhide, S.K. Kaicker, J. Chem. Phys. 35, 695 (1974). 
[7] A.K. Dey, B.K. Agarwal, Nuovo Cimento Lett. 1, 803 (1971).

[8] S.V. Adhyapak, A.S. Nigavekar, J. Phys. Chem. Solids 37, 1037 (1976).

[9] U.C. Srivastava, H.L. Nigam, Coordination Chem. Rev. 9, 276 (1973).

[10] M. Kitamura, H. Chen, J. Phys. Chem. Solids 52, 731 (1991).

[11] K. Ławniczak-Jabłońska, R.J. Iwanowski, Z. Gołacki, A. Traverse, S. Pizzini, A. Fontaine, Physica B 208\&209, 497 (1995).

[12] K. Ławniczak-Jabłońska, R.J. Iwanowski, Z. Gołacki, A. Traverse, S. Pizzini, A. Fontaine, I. Winter, J. Hormes, Phys. Rev. B 53, 1119 (1996).

[13] B.K. Teo, EXAFS: Basic Principles and Data Analysis, in series Inorganic Chemistry Concepts, Vol. 9, Springer, Berlin 1986.

[14] J.A. Bearden, A.F. Burr, Rev. Mod. Phys. 39, 125 (1967). 